\title{
SOBRE CATEGORIAS E FRONTEIRAS
}

\section{On categories and boundaries}

\author{
Adelaide Hercília Pescatori Silva*
}

\begin{abstract}
RESUMO
Este artigo toca num problema colocado por modelos teóricos que impõem fronteiras discretas sobre fatos relacionados à experiência humana ao tentarem explicar tais fatos. $\mathrm{O}$ artigo trata em especial da Fonética, disciplina da Linguística dedicada aos sons da fala, e parte do exemplo fornecido pelas "línguas assobiadas" para ilustrar um fato que se localiza entre duas categorias, como a fala e a música. Até agora, os assobios não eram considerados sons da fala e, portanto, eram excluídos do escopo do objeto de estudo da Fonética. Por outro lado, assobios podem ser combinados em cadeias dotadas de significado, em línguas como a da ilha de la Gomera. Portanto, há fortes evidências de que os assobios se comportem como sons da fala. O problema é que os modelos disponíveis não conseguem acomodar fatos como assobios, porque tais modelos assumem a existência de fronteiras estritas. Assim, o argumento neste trabalho é o de que assobios - considerando os exemplos aqui discutidos - podem ser melhor explicados num arcabouço teórico que assume a inexistência dessas fronteiras estritas. Este, aliás, é o ponto de partida de sistemas complexos. Assumir a fala como um sistema adaptativo complexo - como se propõe aqui - pode permitir que sons de fala "canônicos" e assobios tenham um tratamento unificado.
\end{abstract}

Palavras-chave: fonética; fronteiras; sistema complexo.

\begin{abstract}
This paper addresses the problem raised by theoretical models that impose discrete boundaries on facts with regard to human experience in their attempt to explain such facts. The paper

* Universidade Federal do Paraná
\end{abstract}


focuses especially on Phonetics, the field in Linguistics devoted to the sounds of speech, and departs from the example provided by whistled languages to illustrate a fact that lays beyond two categories, such as speech and music. So far, whistles have not been included into the set of sounds Phonetics assumes to be its object of investigation. On the other hand, whistles can be combined into strings with a meaning, in languages such as the one from la Gomera Island. Thus, we have strong evidence that whistles behave as speech sounds. The problem is that present theorical approaches cannot accommodate them, because such approaches assume the existence of hard boundaries. So, we argue here that whistles - taking into account the cases presented here - can be better explained in a theoretical framework that assumes that there are no hard boundaries. The absence of hard boundaries is the departing point of complex systems. So, we argue that whistles and "canonic" speech sounds can have a unified approach if we assume speech to be a complex adaptive system.

Keywords: phonetics; boundaries; complex system.

\section{INTRODUÇÃo}

O convite para participar do "Colóquio Letras e Filosofia: por uma análise naturalista da narrativa”, me deixou muito satisfeita, especialmente pelo caráter multidisciplinar do evento e pela perspectiva de interlocuções instigantes. O convite veio acompanhado de um desafio: o pedido para que eu sistematizasse as discussões ali conduzidas, buscando um ponto comum entre elas. E esse era mesmo um grande desafio porque, embora houvesse um tema comum ao evento, as discussões a que assistimos foram ao mesmo tempo tão diversas, mas tão ricas, que encontrar um ponto de interseção entre elas mostrou-se uma tarefa nada trivial.

Este texto, então, é fruto de reflexões surgidas a propósito do Colóquio. E mais do que tratar de narrativa, propriamente, ele extrapola esta questão, apresentando minha leitura do que possa ter sido o ponto comum entre as apresentações. E vai além: como as apresentações suscitaram-me reflexões sobre o que se faz na minha própria área de atuação, parto do que identifico como um fio condutor do Colóquio para pensar questões que têm sido alvo de preocupação dos foneticistas. E é curioso pensar que a fonética talvez seja a área da linguística que mais se aproxima de um enfoque naturalista. Curioso porque esse enfoque, que volta à cena, excluiu a fonética da ciência linguística por muitos anos. E é ele quem se encarrega de alçar 
a fonética a um patamar de vanguarda na linguística, nos últimos anos, ao possibilitar uma discussão multidisciplinar sobre fronteiras entre disciplinas dessa ciência.

Esta reflexão deve se tornar mais clara no decorrer do texto. Por ora, cabe-me esclarecer que ela advém da observação de que a tônica das discussões durante o Colóquio me parece poder ser resumida pela observação concernente à dificuldade de se contemplar fatos relacionados à linguagem - como as narrativas - lançando mão das categorias analíticas disponíveis e propostas pelos arcabouços teóricos vigentes, que não raro são o main stream das áreas às quais se circunscrevem.

É certo que o estabelecimento de categorias para falar do mundo parece uma necessidade do ser humano, nos mais variados campos do conhecimento. Tomemos a percepção visual das cores como exemplo deste argumento: a física nos ensina que o espectro cromático é contínuo porque a cor é determinada pelos diferentes comprimentos de onda do espectro eletromagnético, e o comprimento das ondas é contínuo. Entretanto, e em função de limitações que nossos órgãos de visão nos impõem, nós não conseguimos captar o contínuo pelo qual se estendem as ondas do espectro eletromagnético, mas pontos nesse contínuo. Por isso, podemos dizer que nossa percepção visual impõe pontos discretos ao espectro eletromagnético e, assim, nós reconhecemos categorias de cores. Como consequência, podemos ter categorias mais "largas" como vermelho ou azul, da mesma forma que podemos ter categorias mais "estreitas", como "vermelho sangue"; "vermelho cereja"; "azul-marinho"; "azul anil". De qualquer modo, o que orienta uma e outra réguas são pontos discretos.

E, desta forma, chegamos a um ponto crucial para as reflexões aqui apresentadas: a exemplo do que fazem com o espectro cromático, os seres humanos impõem categorias sobre qualquer outra coisa no mundo. A linguagem e suas manifestações não fogem a essa regra. Então, nesse quesito, podem-se estabelecer categorias como "obras inovadoras" e "obras não-inovadoras"; "sentido literal" e "sentido metafórico"; "fala" e "música". Entretanto, o estabelecimento de categorias, no que toca especialmente à linguagem, não é matéria consensual, livre de problemas. Afinal, há sempre exemplos de fatos que parecem caber, concomitantemente, em duas categorias. É o caso das "línguas assobiadas", de que este artigo tratará mais adiante, e que colocam em xeque a fronteira entre as categorias "fala" e "música". No limite, exemplos assim dificultam nossa compreensão sobre o fato investigado, muito provavelmente em razão do reducionismo que as categorias impõem sobre o objeto de estudo. Não defendo, com esta afirmação, que uma investigação científica e os modelos teóricos que a embasam devam ser capazes de contemplar o objeto de estudo em sua totalidade. 
Isto é impossível. O argumento, neste caso, é outro, e parece em alguma medida compartilhado pelos participantes do Colóquio: uma abordagem que reconheça o caráter gradiente de um fato e que tente explicá-lo sem impor categorias a ele, pode conseguir uma melhor compreensão sobre tal fato.

A explicação dos fatos gradientes, por sua vez, não é trivial e comumente requer que se recorra a arcabouços teóricos e aparatos analíticos de outras disciplinas, diferentes daquela que se debruça sobre o fato. Neste sentido, a criação de interfaces entre áreas diferentes é fundamental.

Este artigo toma o caso específico da fonética, nas próximas seções, para desenvolver o argumento esboçado nos parágrafos precedentes. E, na última seção, traça uma relação possível com os estudos de narrativa, tomando a perspectiva naturalista como mote.

Por que tomar a fonética como exemplo, afinal? Porque esta disciplina da linguística, que toma os sons da fala como objeto de estudo, precisa entender como esses sons são produzidos. Para isto, é necessário estabelecer interfaces com áreas como a física, a fisiologia ou a psicologia, por exemplo. A seção seguinte trata de apresentar as razões dessas interfaces e como elas se fazem.

\section{2 - A FONÉTICA: DISCIPLINA DE INTERFACES}

Dizer - como na seção anterior - que a fonética toma como seus objetos de estudo os sons da fala, requer que se abordem duas questões inicias: "como nós, humanos, falamos?" e "quais são os sons da fala"?

\section{1 - Como nós FALAmos?}

Para tentar responder a essa questão, recorremos a MacNeilage (2008), que nos diz:

The number of different muscles in the speech apparatus - the chest, larynx, throat, mouth, and face - totals about forty. Not all these muscles work for all sounds, of course, but even assuming that just fifteen have to change what they are doing for each successive sound, this would mean that about 225 different muscle activations would occur in each second of speech. That averages one event every 5 milliseconds! And add to this the fact that we can't simply think of the same set of about fifteen muscle actions for each individual consonant and vowel whenever they are produced. The muscles used will vary depending not only on what sound comes before the consonant or vowel in question, but also on what 
O excerto deixa evidente que a produção da fala é um processo resultante da ação de diversos músculos, portanto, e obviamente, fisiológico. Por outro lado, a escolha dos músculos que devem ser ativados para a produção de um determinado som, assim como a coordenação entre os movimentos dos músculos, para a produção desse som, envolvem processos neurológicos, responsáveis pela ativação de um conjunto de músculos durante um determinado período de tempo. Deve ficar clara, a partir destas considerações de MacNeilage (2008), que a compreensão sobre o modo como um som qualquer é produzido requer um conhecimento mínimo de fisiologia. Assim, por exemplo, não se pode fazer fonética sem saber que, para produzirmos um som como [d], é preciso elevar a língua até que encoste nos alvéolos. Note, porém, que não é a língua toda que se eleva, mas a porção frontal dela, ou ponta da língua. E esse movimento, por sua vez, precisa se coordenar, no tempo, com o movimento das pregas vocais, que vibram.

Há que se adicionar que o movimento dos músculos do aparelho fonador tem consequências acústicas: basta considerar que o fluxo de ar egresso dos pulmões, durante a produção dos sons da fala, passa por uma cavidade - o trato vocal - que assume diferentes formatos, em razão do movimento dos articuladores. Ora, o trato vocal funciona como uma caixa de ressonância do som produzido pela vibração das pregas vocais. O som, por sua vez, se propaga por ondas. Estas, ao chegarem ao trato, assumirão formatos e comprimentos distintos como resultado do tamanho e do formato da caixa de ressonância. Existe, portanto, uma relação direta entre o movimento dos articuladores e as características acústicas dos sons por eles produzidos. Esta observação é o ponto de partida da Teoria Acústica de Produção da Fala (Fant, 1960), que embasa as caracterizações acústicas dos sons da fala que se faz ainda hoje mundo afora.

Cabe acrescentar que, apesar da complexidade do processo de produção da fala, advinda da grande quantidade de músculos envolvidos na tarefa, nós não nos damos conta do processo: não pensamos quais músculos temos de acionar para produzir um som, nem na maneira como

1 "O número de músculos diferentes no aparelho fonador - a caixa torácica, a laringe, a boca e a face - totaliza quase quarenta. Obviamente, nem todos estes músculos são acionados para a produção de todos os sons, mas mesmo assumindo que apenas quinze tenham de mudar o que estão fazendo para produzir sons sucessivos, teríamos um total de 225 ativações musculares diferentes e necessárias para a produção de cada som da fala. Isto dá, em média, um evento a cada cinco milissegundos! Acrescente-se a isto o fato de que não podemos considerar sempre o mesmo conjunto de aproximadamente quinze ações musculares para cada consoante e cada vogal, a cada vez que são produzidos. Os músculos geralmente variam a depender não só do som que precede a consoante ou a vogal em questão, mas também do som que a sucede." (Tradução minha) 
devem ser coordenados e por quanto tempo devem permanecer ativados. Nós simplesmente falamos.

Saltzman e Kelso (1987) propõem uma Teoria Motora de produção da fala justamente para tentar explicar este último ponto: para a Teoria Motora, a ação dos articuladores para a produção de um som da fala é um processo simbólico, internalizado, que assume esse estatuto como resultado da repetição de padrões de movimentos.

Para ilustrar esse argumento, Saltzman e Kelso (1987) recorrem ao aprendizado de uma outra habilidade motora: o ato de beber uma xícara de café. Esta ação corriqueira esconde, ao fim e ao cabo, tarefas motoras complexas, que nós automatizamos ao ponto de não nos darmos conta do que é preciso fazer para tomarmos um cafezinho. Assim, para isso são necessários comandos motores que acionam os músculos de braço e antebraço, pelo menos, para levarmos a mão em direção à xícara. Novos comandos neuromotores possibilitarão que a mão se aproxime da xícara. Para movimentar os dedos que prenderão a xícara, precisamos acionar outros músculos e, por conseguinte, novos comandos motores são necessários. E a tarefa não para aí: o ato de levar a xícara até a boca requer a ação de alguns outros músculos, assim como o ato de inclinar a xícara para verter o café na boca. É importante acrescentar que os movimentos de cada conjunto de músculos, durante cada um dos passos brevemente descritos, têm um tempo de ativação e uma magnitude determinados. Um "erro de cálculo" pode, por exemplo, fazer o indivíduo verter café na própria roupa. Além do que já se disse, há que se acrescentar que os movimentos são coordenados no tempo: de nada adianta eu ter realizado o movimento de preensão da xícara se eu não tiver, antes, levado minha mão até ela.

Note-se que é necessário um processo de aprendizado para que um indivíduo consiga tomar um cafezinho. E o aprendizado é um processo lento, tanto que um bebê, por exemplo, não consegue realizar essa tarefa e leva algum tempo para aprendê-la. $O$ aprendizado se faz pela repetição dos padrões de movimentos. Uma vez aprendidos, esses padrões são automatizados e, por conseguinte, internalizados. É a internalização dos padrões motores envolvidos em todo o ato de tomar um cafezinho que nos exime da necessidade de pensar em cada movimento a cada vez que decidimos tomar um café.

A Teoria Motora prevê que a produção dos sons da fala obedece a um procedimento análogo ao descrito. Assim, para produzirmos o som [s], precisamos elevar a ponta da língua em direção à região dos alvéolos, logo atrás dos dentes incisivos superiores. A elevação da língua vai a um ponto máximo de aproximação com os alvéolos sem, no entanto, tocá-los. Além disso, as pregas vocais devem permanecer afastadas, sem vibrarem. Há, por- 
tanto, a necessidade de coordenar, pelo menos, movimento de pregas vocais e de ponta de língua. E a magnitude do movimento da ponta da língua deve ser tal que haja grande aproximação entre esse articulador e os alvéolos, sem que a ponta da língua toque os alvéolos.

E se o falante "errar" o movimento e encostar a ponta da língua nos alvéolos? Neste caso, deixaremos de ter [s] como resultado do processo e teremos [t]. Note, portanto, que a alteração da magnitude do movimento da ponta da língua muda, no caso deste exemplo, o som visado. Assim como no processo de aprendizado de beber líquidos em copos ou xícaras, o processo de aquisição de linguagem é um processo lento e que demanda - assumindo-se os princípios da Teoria Motora - a repetição de padrões de movimentos dos articuladores do trato. A repetição de padrões motores leva à sua internalização e, uma vez internalizados, os padrões são acionados no momento da produção de um som, sem que precisemos recuperar todos os passos necessários à sua produção. Nós simplesmente o articulamos. E fazemos isso de maneira tão automática que, ainda conforme MacNeilage (2008:04), conseguimos produzir aproximadamente quinze consoantes e vogais por segundo, organizadas precisamente em sequências maiores, como as sílabas.

Do que foi dito até aqui, deve ter ficado clara a necessidade de interlocução da fonética com a física, a fisiologia e a psicologia: para entender como um som é articulado e quais são as consequências de um movimento diferente do esperado para a articulação de um som - vide o exemplo da produção de [t] em substituição a [s], supramencionado - é preciso ter noções de fisiologia. Por outro lado, as noções de acústica permitem prever as consequências de se ter um estreitamento severo no trato, durante a produção de [s], bem como as consequências de se ter uma obstrução à passagem do fluxo de ar no trato, durante a produção de [t]. Permitem, ainda, descrever os sons decorrentes de cada uma dessas manobras articulatórias através de parâmetros como a frequência do ruído de [s] ou a frequência do som no momento da soltura dos articuladores logo em seguida à obstrução necessária para a articulação de [t]. Por último, a psicologia cognitiva fornece ferramentas para se pensar como falamos, ou melhor, como implementamos nossas ações motoras, desde o momento em que as planejamos (i.e., desde o momento em que "decidimos" que devemos produzir um [s], por exemplo) até o momento em que as executamos.

A internalização dos padrões motores envolvidos na produção de um som da fala alça o som ao nível simbólico, abstrato. É preciso observar que, ao alcançar o nível simbólico, os padrões motores presentes na produção de um som ganham, por consequência, um caráter discreto. Ou seja, parte-se de um estado em que existe uma variabilidade de produção - afinal 
é impossível posicionar os articuladores precisamente no mesmo ponto do trato, a cada vez que se repete um padrão motor - para se atingir um estado de invariância.

Para a linguística, as unidades invariantes têm suma importância, porque no limite estabelecem distinções de sentido entre duas cadeias sonoras, como no caso das sequências /'a.sa/ (flexão do verbo "assar") e / 'a.ta/ (flexão do verbo "atar"). Isto quer dizer, em última instância, que os movimentos dos articuladores são postos a serviço da gramática de uma língua, para diferenciar significados.

o que eu estou dizendo, aqui, não é o main stream na linguística, em especial na fonética e na fonologia ${ }^{2}$. Basicamente, eu assumo a posição de que se constrói a gramática fônica (fonologia) de uma língua a partir da experienciação dos indivíduos, isto é, da articulação dos sons. Ou, colocando de outra forma: a fonologia se constrói a partir da fonética.

Esta perspectiva se liga intimamente a uma concepção naturalista de fala e se contrapõe a uma outra concepção de língua e fala.

Para uma melhor compreensão das duas vertentes, voltemos a MacNeilage (2008) que, na epígrafe do capítulo introdutório de sua obra, traz as duas citações transcritas abaixo:

In the distant future I see open fields for far more important researches. Psychology will be based on the foundation... of the necessary acquirement of each mental power and capability by gradation. Light will be thrown on the origin of man and his history3. Charles Darwin, The Origin of Species (1859/1952), p. 243.

You can't just assume that because something's there it is functional, or has been adapted for.. It could be just there ${ }^{4}$.

Noam Chomsky, apud MacFarquhar, 2003, p.71

As considerações de Darwin embasam uma concepção evolucio-

2 A título de esclarecimento e especialmente a um leitor pouco familiarizado com a linguística: fonética e fonologia são duas disciplinas da linguística que tomam um mesmo objeto de estudo, que é o som da fala. A dissociação entre ambas as disciplinas - herdada do estruturalismo e ainda adotada por muitos modelos, inclusive de inspiração gerativa - prevê, em linhas gerais, que a fonética tenha um caráter descritivo e a fonologia tenha um caráter explicativo. Assim, enquanto à fonética caberia descrever as propriedades articulatórias e acústicas dos sons da fala, à fonologia caberia investigar as relações entre sons numa dada língua (vide, e.g. Souza e Santos, 2003). Esta não é a perspectiva orientadora deste artigo. Ao contrário, o artigo segue uma perspectiva que prevê a comensurabilidade entre fonética e fonologia.

3 "No futuro distante eu vejo campos abertos para pesquisas mais importantes. A psicologia se baseará nos fundamentos... da aquisição necessária de cada capacidade mental por gradação. Luz será lançada sobre a origem e a história do ser humano." (Tradução minha.)

4 "Não se pode simplesmente assumir que, porque algo que existe é funcional ou foi adaptado para... Esse algo pode simplesmente estar lá.” (Tradução minha.) 
nista da fala. Essa concepção é adotada pelo próprio MacNeilage (2008), bem como por outros pesquisadores, como Saltzman e Kelso (1987) ou Browman e Goldstein (1992), em sua proposta de uma Fonologia Gestual. Por essa concepção, a fala é resultado de um processo adaptativo ocorrido durante a evolução da espécie humana. Ou seja, admite-se que a fala surge como consequência da adaptação de certos órgãos do corpo humano para a função específica de produzir sons da fala. Nunca é demais lembrar que nós não temos órgãos especializados na produção dos sons da fala, mas que "tomamos emprestados" do sistema digestório e do sistema respiratório alguns órgãos que, além de sua "função default", passaram também a desempenhar essa outra tarefa, o que constitui um processo de exaptação. Porém, para isso foi preciso que se adaptassem a essa finalidade específica, num processo evolutivo lento.

Não há como saber ao certo quando e como começou essa adaptação. Mas é possível rastrear fatos mais recentes, para tentarmos entender um pouco sobre a maneira como os sons da fala dos seres humanos se desenvolveram. Assim, por exemplo, pesquisadores que tentam reconstruir a fala dos Neandertais, como Patsy Rodenburg ${ }^{5}$, observam que sua fala era aguda, anasalada e de volume alto, bem diferente da fala dos seres humanos atuais. Aguda em razão da posição mais alta que a laringe ocupava no trato vocal. Isto promovia a produção de sons com maior frequência: como o trato vocal - a cavidade de ressonância pela qual se propaga o fluxo de ar - tinha extensão menor, consequentemente as ondas sonoras que se propagavam por ele tinham menor comprimento de onda e a frequência dos sons em geral era, então, mais alta.

A cavidade torácica grande, aliada ao crânio também grande e pesado, por um lado possibilitavam uma força expiratória maior para o fluxo de ar e, por outro, no caso específico do crânio, serviam como um grande amplificador para os sons da fala. A qualidade anasalada da fala do Neandertal, por sua vez, resultava da cavidade nasal grande que possibilitava a propagação de maior fluxo de ar nasal, conferindo essa qualidade à voz dos Neandertais. Com a evolução da espécie, e a consequente diminuição da cavidade nasal e da caixa torácica nossa voz ficou menos anasalada e com volume mais baixo. A diminuição do tamanho do crânio, por outro lado, possibilitou uma postura mais ereta. Então, a laringe fica mais baixa no trato, aumentando seu tamanho. E a voz dos humanos torna-se menos aguda.

Também pudemos - com o auxílio de outros órgãos que igualmen-

5 Coordenadora de Voz do Guildhall School of Music and Drama. Um vídeo da BBC de Londres, sobre o trabalho dessa pesquisadora, referente à fala dos Neandertais, pode ser acessado em https://www.youtube.com/watch?v=NmevKV4iOaA 
te foram se adaptando à produção da fala - passar a articular certos sons que, combinados a outros, passaram a constituir sequências, às quais o ser humano passou a atribuir significado. Assim começamos a falar.

\section{2 - QUAIS SÃO OS SONS DA FALA?}

É facilmente observável que o trato vocal, esse aparato que desenvolvemos ao longo da história da espécie humana, tal como o conhecemos hoje, nos permite produzir uma vasta gama de sons. Entretanto, ao investigarmos os sons da fala, uma primeira necessidade - talvez óbvia - é estabelecer quais são eles, pois é isto que interessa a disciplinas como fonética e fonologia. $O$ interesse está relacionado ao fato de que faz parte do objeto de estudo de ambas as disciplinas investigar com quais outros sons um dado som se combina para formar unidades maiores e por quê. Ou quais são as sequências de sons não permitidas numa dada língua. Ou, ainda, quais desses sons ocorrem no núcleo e nas margens de uma sílaba.

O conjunto de sons da fala, no geral, é definido por oposição àqueles que não seriam sons da fala. Um dos critérios que embasa a oposição é a constatação de que os sons da fala se combinam entre si, encadeando-se e formando sequências maiores, às quais se atribui sentido, como palavras. Ou seja, sons que assumem uma função linguística numa língua qualquer. Baseados nesse critério, Ladefoged e Maddieson (1996, p. 2) afirmam, ao apresentarem seu The sounds of the world's languages:

There are, of course, many sounds that can be made with the vocal organs that are not known to be used in any language. People can whistle, click their teeth, wag their tongues from side to side, and perform a variety of other maneuvers to produce sounds that have never been reported to have a linguistic function. But linguistic phonetics does not have to account for all the sounds that humans are capable of making, or even all of those which can be made just in the vocal tract. ${ }^{6}$

Igualmente assumindo o mesmo critério, muitos manuais dedicados ao ensino de fonética afirmam não fazerem parte dos sons da fala

6 "É claro que há muitos sons que podem ser produzidos com os órgãos fonadores e que não são usados em qualquer língua. As pessoas podem assobiar, bater os dentes, mexer a língua de um lado para outro e realizar muitas outras manobras para produzir sons para os quais nunca foi registrada uma função linguística. Mas a fonética linguística não tem de dar conta de todos os sons que os humanos são capazes de fazer, nem mesmo daqueles que podem ser feitos apenas no trato vocal." (Tradução minha.) 
produções como tosse ou assobio ${ }^{7}$. Consequentemente, essas produções estariam fora do escopo da fonética.

Entretanto, a documentação de alguns registros oferece contra-argumentos ao critério comumente utilizado para se definirem os sons da fala. Um exemplo possível de contra-argumento é a hum language, empregada pelos pirahã ${ }^{8}$ usando apenas uma produção como "hum", mas modulando sua frequência, de modo a obter uma espécie de melodia com essa estratégia, o registro serve à comunicação entre indivíduos, que aparentemente atribuem sentido às diferentes modulações desse som, sem encadeá-lo com outros sons para constituir sequências dotadas de significado. Note que, em português brasileiro (PB), por exemplo, usamos esse som para expressar concordância com algo. Este, porém, é o único contexto de uso do som em PB. O pirahã, por outro lado, permite que se elaborem enunciados com esse som, através da modulação de sua frequência.

Outro contra-exemplo para afirmações como a de Ladefoged e Maddieson (1996) são as whistled languages, ou "línguas assobiadas". Como o próprio nome diz, as línguas assobiadas são registros através dos quais se veicula uma mensagem através de assobios.

o que chama particularmente a atenção nas línguas assobiadas, como a da Turquia ${ }^{9}$, a da Ilha de la Gomera ${ }^{10}$, nas Canárias, é que elas parecem ter dois pontos em comum: 1) parecem servir para comunicação à distância. No caso específico das duas primeiras, são utilizadas em terrenos montanhosos, o que parece se coadunar com o argumento de Everett (2013), segundo o qual o meio geográfico teria um papel fundamental na determinação dos sons da fala numa e noutra língua; 2) as modulações de frequência dos assobios carregam significado, que é compartilhado pelos usuários desses registros. Tanto é assim que se podem "traduzir" os assobios, como se vê nas legendas dos vídeos sugeridos nas notas 5,6 e 7 .

A questão inevitável que essas línguas colocam à linguística é: como tratar delas? Afinal, se temos sequências sonoras às quais se atribui um sentido e esta informação é compartilhada por um grupo de indivíduos, parece inegável que os assobios, nestes casos, sejam sons das línguas, contrariamente à afirmação de Ladefoged e Maddieson (1996), seguida por muitos manuais de fonética, como já afirmado. Mas a teoria linguística não

7 A esse respeito vide, e.g., Maia (1986) ou Silva (2007).

8 Os pirahã são um povo indígena brasileiro que habita uma região do município de Humaitá (AM). Para uma amostra do registro vocal citado, vide https://www.youtube.com/ watch?v=KYpjFObtV94

9 Para uma amostra dessa língua, o leitor pode acessar https://www.youtube.com/ watch? $\mathrm{v}=$ SjcVLLdPCoU

10 Para uma amostra dessa língua, o leitor pode acessar https://www.youtube.com/ results? search_query $=$ whistled + language + of + the + island + of + la + gomera 
dispõe de modelos que acomodem tais produções, muito provavelmente em razão de os sons dessas línguas ocuparem a fronteira entre música e fala. Há ainda um outro problema: como delimitar os "pedaços" dos assobios, dotados de sentido, e que combinados a outros "pedaços" produziriam unidades maiores? Diferentemente dos sons como [s] ou [t], as "modulações" dos assobios, como tenho grosso modo chamado aqui às variações de frequência, têm uma delimitação mais difícil, porque mudam rápida e continuamente no tempo. Sons como [s] ou [t], por sua vez, têm traços acústicos bem claros: enquanto [s] se caracteriza por ruído, nitidamente visível no sinal de fala, seja pelo formato irregular da onda, seja pelo aspecto "chuviscado" num espectrograma, $[t]$ exibe uma porção sem energia de produção, tanto na forma da onda, como num espectrograma, devido ao encontro entre ponta de língua e alvéolos, que impede a passagem do fluxo de ar pelo trato vocal. Os assobios não são assim: como já observado, serão sons contínuos nos quais a principal mudança será a frequência de vibração das pregas vocais.

Ao fornecerem evidência de que assobios podem ser considerados sons da fala, as línguas assobiadas suscitam duas questões importantes: 1) como representar os assobios na gramática fônica, i.e., na fonologia de uma língua? 2) como dar conta de fatos que não se encaixam, propriamente, em uma ou em outra categoria, e.g. fala e canto, mas reúnem características de mais de uma categoria a um só tempo?

Em última instância, o que se pergunta é: como um fato contínuo e dinâmico como os assobios podem ser discretizados? A pergunta pressupóe que a discretização seja necessária em razão de um comentário na introdução deste artigo: a necessidade de os seres humanos estabelecerem categorias para falarem do mundo.

\section{3 - DisCRETIZAÇÃo DE FATOS GRADIENTES}

A resposta à pergunta que fecha a seção precedente não é simples e também não está pronta, porque os modelos de análise fonológica, majoritariamente, assumiam que os sons da fala são unidades discretas. Recentemente, nos últimos vinte anos, é que a literatura fonética tem fornecido mais e mais evidências sobre o caráter contínuo, gradiente, dos sons da fala ${ }^{11}$ e que se passa a conseguir dar conta de sons que, aparentemente, reúnem características de mais de um som, mas não são propriamente nem um, nem outro.

11 Para exemplos de trabalhos que trazem essas evidências, o leitor pode consultar, por exemplo, Silva (2002). 
Também nestes últimos vinte anos é que a literatura fonológica, inspirada especialmente pela vertente que se convencionou chamar "fonologia de laboratório" ${ }^{2}$, passa não só a olhar para o dado fonético mas, sobretudo, a tentar incorporá-lo a um modelo de análise.

É a perspectiva de unir fonética e fonologia, tornando-as comensuráveis, que orienta as considerações nesta seção sobre como discretizar fatos-limite, a exemplo dos colocados por uma língua assobiada.

Antes de mais nada, é preciso considerar que não parece haver outro modo de contemplar fatos-limite a não ser assumindo uma concepção "à la Darwin", como a expressa na seção 2.1 deste artigo, i.e., uma concepção de que os assobios de línguas como o Pirahã ou o Silbo Gomero, usado na ilha de la Gomera, resultam da adaptação evolutiva dos órgãos fonadores para a produção daqueles sons. E, mais, de que a adaptação esteve sujeita a requisitos do ambiente, como a topografia acidentada da ilha do arquipélago das Canárias ou das montanhas da Turquia, por exemplo.

A outra concepção sobre a gênese das línguas e dos sons da fala, segundo a qual esses são fatos que "estão lá" e simplesmente emergem na história de um indivíduo, não permitiria pensar nos fatos-limite, porque seria necessário prever um conjunto muito extenso de regras que "convertessem" o fato discreto no fato gradiente. Isto supondo que tal conjunto conseguisse, de fato, operar a conversão.

Assumindo uma concepção evolutiva de língua e assumindo, igualmente, que os sons da fala resultam de um processo adaptativo, para $o$ qual fatos como o ambiente em que se inserem os indivíduos que produzem tais sons, é necessário assumir que a fala é um sistema em que diversas variáveis interagem. Logo, é necessário conceber a fala como um sistema complexo. Por sistema complexo entende-se um sistema cujas propriedades resultam da interação entre diversas variáveis - e não de características isoladas. Tal interação se dá de forma que a alteração numa das variáveis provoca alteração em todo o sistema. Ao fim e ao cabo, a alteração numa variável do sistema pode até gerar novos sons, para ficarmos nos exemplos que temos tomado aqui.

Assim, teríamos um sistema em que variáveis como, por exemplo, "distância física entre indivíduos" interage com variáveis fisiológicas, como "órgãos do trato vocal envolvidos na produção de um som"; variáveis acústicas como "frequência do som" e variáveis psicoacústicas, como "saliência perceptual"13. Por hipótese, e considerando, como mencionado acima, que

12 Sobre a fonologia de laboratório, suas bases, seus objetivos e sua metodologia analítica, o leitor pode consultar Pierrehumbert, Beckman e Ladd (2000).

13 Por saliência perceptual entende-se, como Lindblom (1990), a maior facilidade que 
a alteração numa variável provoca a alteração de todo o sistema, devido à interação entre as variáveis, a variável "distância física entre dois indivíduos", por exemplo, pode provocar a alteração de todo o sistema caso ela seja longa ou caso os dois indivíduos habitem um território onde há muitos obstáculos, como árvores ou montanhas, ainda para pensar nos exemplos tomados até aqui.

Cabe notar que, neste cenário, é possível pensar na adaptação dos órgãos do trato vocal, durante a evolução dos seres humanos, habitantes dos locais mencionados neste artigo, para a produção dos assobios utilizados com fins de comunicação. Mas, para além de uma evolução fisiológica, há que se pensar também numa evolução cognitiva, que permitiu a atribuição de sentido a assobios com características físicas diferentes.

$\mathrm{E}$, neste ponto, tocamos especialmente na discretização de aspectos dos assobios. Uma hipótese possível, assumindo a concepção de língua já exposta, e baseada num modelo como a Teoria Motora (Saltzman e Kelso, 1987), é a de que os "padrões" de assobios vão sendo adquiridos durante o desenvolvimento dos indivíduos. E que a repetição de padrões leva à sua fixação. O processo de aquisição dos padrões consiste num "treino" de coordenação dos movimentos dos articuladores, até que se estabeleçam padrões de movimento. Os padrões se estabelecem no momento em que os movimentos dos articuladores estão devidamente sintonizados de modo a cumprir a tarefa de articular o som visado.

Para o indivíduo saber se conseguiu ou não sintonizar os movimentos dos articuladores, a interação com outros usuários da língua e a propriocepção são fundamentais, pois dão ao indivíduo as pistas necessárias para que ele saiba se cumpriu ou não a tarefa visada e, caso não a tenha cumprido, o que pode ser necessário para que ele ajuste sua produção às produções do grupo. Deve-se esclarecer que esta hipótese se baseia na proposta de Browman e Goldstein (1989) para o estabelecimento dos padrões de movimentos sonoros nas línguas e que resultam, em última instância, nos sons empregados por uma dada língua. É um processo que parte da experienciação do indivíduo, do que é variável, portanto, e ruma à construção do discreto, do simbólico. Albano (2001) denomina tal processo "aprender fazendo".

A repetição de padrões de movimento para a aquisição de sons como [s], ou dos assobios, conjugada à perspectiva de que sua aquisição

um som exibe para ser percebido pelo ouvido humano. Neste sentido, no caso específico das línguas assobiadas, pode-se pensar que elas sejam propícias para comunicação à distância, num terreno acidentado como, por exemplo, o Silbo Gomero, porque os assobios têm frequência mais alta do que os sons da fala. 
parte da experienciação, explica possíveis variações de produção, bem como uma eventual "curva em U" durante o processo de aquisição, i.e., um aparente retrocesso no processo, que se revela no momento em que um som que parecia adquirido "desaparece" da fala do indivíduo que adquire o sistema sonoro de uma língua.

Uma vez fixada a sintonia entre os movimentos dos articuladores, o padrão dos movimentos é internalizado de tal modo que o acessamos já "pronto", sem necessidade de calcular todos os movimentos a cada nova produção de um som. A analogia com a tarefa de tomar uma xícara de café, portanto, é perfeita. Essa internalização é que discretiza o fato, i.e., que torna simbólico um fato motor. Com ela, temos a imagem mental do que precisa ser feito para realizar uma tarefa motora qualquer.

\section{4 - CONSIDERAÇões FinAIS}

Até aqui, observamos a necessidade das interfaces para dar conta não só da produção dos sons da fala, mas também da maneira como se constrói sua imagem abstrata, tomando para isso um exemplo limítrofe entre duas categorias - nomeadamente fala e música - que são os assobios presentes no que se convencionou chamar línguas assobiadas (whistled languages).

Quisemos com isto mostrar a dificuldade em se estabelecerem fronteiras claras entre categorias, além da dificuldade em fornecer um tratamento para esses exemplos limítrofes.

$\mathrm{O}$ argumento central que embasa as reflexões aqui conduzidas é que para tratar de forma minimamente adequada dos assobios que são também sons da fala em algumas línguas, é preciso considerar que os sons da fala não são fatos "especiais", que emergem sem uma aparente causa, mas que decorrem de uma adaptação evolutiva pela qual passaram os órgãos que especializamos para fonação, ao longo da história da espécie humana.

Deve ficar claro, portanto, que se segue, no curso deste argumento, uma perspectiva naturalista, mesma perspectiva norteadora das reflexões apresentadas durante o Colóquio Letras e Filosofia: Dolabela ${ }^{14}$, e.g., argumenta que a evolução biológica é culturalmente condicionada.

Ora, esta é uma perspectiva que se aproxima da perspectiva aqui desenvolvida à medida que prevemos que a adaptação dos assobios para desenvolverem a função de sons da fala, aos quais se atribui um sentido, pode ser condicionada pelo meio no qual os usuários das línguas assobiadas habitam (c.f., e.g., Everett, 2013) e que a atribuição de sentido a um assobio

14 Comunicação pessoal. 
ou a uma sequência de assobios é um fato culturalmente determinado, já que os usuários daqueles sons "combinam tacitamente", através do uso reiterado, qual sentido será atribuído a qual assobio.

Um outro ponto, igualmente tocado no Colóquio, é o de que o romance cumpriria, na escrita, o papel de trazer aos indivíduos fatos de narrativa oral. Neste sentido, talvez não seja arriscado dizer que a fala está a serviço da narrativa, tanto no percurso histórico da espécie humana como no percurso histórico do indivíduo. Assim sendo, é possível pensar que certos sons podem ser utilizados numa narrativa oral com um fim específico, pertençam eles ou não ao conjunto dos sons de uma determinada língua. Como eles são usados - e como são adaptados a uma determinada função de uso - pode ser uma interseção possível entre os estudos fonéticos e os estudos da narrativa. E esta intersecção pode abrir portas para uma interdisciplinaridade ainda incipiente, mas certamente promissora e profícua e que busque não estabelecer fronteiras entre fatos.

\section{REFERÊNCIAS}

ALBANO, Eleonora. O gesto e suas bordas: esboço de Fonologia Acústico-Articulatória do português brasileiro. Campinas: Mercado de Letras/Fapesp, 2001.

BROWMAN, Catherine e GOLDSTEIN, Louis. Articulatory gestures as phonological units. Phonology, 6, p. 201-251, 1990.

. Articulatory Phonology: An Overview. Phonetica, 49, p. 155-18, 1992.

EVERETT, Caleb. Evidence for Direct Geographic Influences on Linguistic Sounds: The Case of Ejectives. PLOS ONE. http://journals.plos.org/plosone/article?id=10.1371\%2Fjournal. pone.0065275, 2013.

LADEFOGED, Peter e MADDIESON, Ian. The sounds of the world's languages. Cambridge (MA): Blackwell, 1996.

LINDBLOM, Björn. Explaining phonetic variation: a sketch of the H\&H theory. In William Hardcastle e Alain Marchal (eds.). Speech production and speech modeling. Dordrecht: Kluwer, 1990. p. 403-439.

MACNEILAGE, Peter. The origin of speech. Cambridge (MA): The Cambridge University Press, 2008.

MAIA, Eleonora Mota. No reino da fala - a linguagem e seus sons. São Paulo: Editora Ática, 1986.

PIERREHUMBERT, Jane; BECKMAN, Mary e LADD, D. Robert. Conceptual Foundations of Phonology as a Laboratory Science. In N. Burton-Roberts, P. Carr and G.J. Docherty (eds.) Phonological Knowledge: Conceptual and Empirical Issues. Oxford: Oxford University Press, 2000. p. 273-303. 
SALTZMAN, Elliot. e KELSO, J.A. Scott. Skilled actions: a task-dynamic approach. Psychological Review, v. 94, n.1, p. 84-106,1987.

SILVA, Adelaide Hercília Pescatori. As fronteiras entre Fonética e Fonologia e a alofonia dos róticos iniciais em PB: dados de dois informantes do sul do país. Tese de doutorado, inédita. IEL/UNICAMP, 2002, $213 \mathrm{p}$.

SILVA, Adelaide Hercília Pescatori. Fonética e Fonologia. Curitiba: IESDE Brasil, 2007.

SOUZA, Paulo Chagas e SANTOS, Raquel Santana. "Fonologia". In José Luiz Fiorin (org.). Introdução à Linguística II - Princípios de análise. São Paulo: Editora Contexto, 2003. 213 p.

Submetido em: 15/03/2016

Aceito em: 28/04/2016 